\title{
Outcome Differences of Remnant-
} Preserving versus Non-Preserving Methods in Arthroscopic Anterior Cruciate Ligament Reconstruction: A Meta-analysis with Subgroup analysis

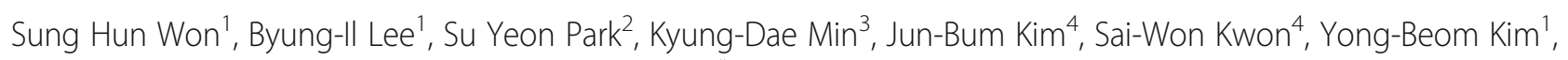
Gi-Won Seo ${ }^{5}$, Jae-Hyung Kim ${ }^{1}$ and Hyung-Suk Choi ${ }^{1 *}$

\begin{abstract}
Purpose: To analyze differences in clinical outcomes of arthroscopic anterior cruciate ligament reconstruction between remnant-preserving and non-preserving methods.

Methods: International electronical databases PubMed, Embase, and the Cochrane central database from January 1966 to December 2017 were searched for randomized controlled trials (RCTs) and observational studies that compared differences of clinical outcomes of $\mathrm{ACL}$ reconstruction with and without remnant preservation. A metaanalysis of these studies was performed to compare clinical outcomes. Subgroup analyses were conducted to evaluate the role of methodological quality in primary meta-analysis estimates.

Results: Five RCTs and six observational studies were included in this meta-analysis and subgroup analysis. The remnant-preserving method in arthroscopic $\mathrm{ACL}$ reconstruction showed a statistically significant difference compared to the non-preserving method regarding arthrometric evaluation (side-to-side difference). Lachman test, Lysholm scores, and IKDC subjective scores showed statistically minor difference in meta-analysis, but showed no significant difference in subgroup analysis. Remained parameters including pivot shift test, IKDC grades, incidence of cyclops lesion showed no statistically differences in meta-analysis or subgroup analysis.
\end{abstract}

Conclusions: This meta-analysis with subgroup analysis showed that arthroscopic remnant-preserving $A C L$ reconstruction provided statistically significant but limited clinical relevance in terms of arthrometric evaluation. Results of Lachman test, Lysholm scores, and IKDC subjective scores demonstrated statistically minor differences.

Keywords: Anterior cruciate ligament, Reconstruction, Remnant preservation, Meta-analysis, Subgroup analysis

\section{Introduction}

Anterior cruciate ligament (ACL) reconstruction is a common procedure. Surgical ACL reconstruction has greatly evolved over the last decades. Current trends are to restore the native ACL anatomy and maintain its functional ability. Preserving the ACL remnant is one of efforts toward more anatomic and biologic reconstruction.

\footnotetext{
* Correspondence: knee@schmc.ac.kr

${ }^{1}$ Department of Orthopaedic Surgery, Soonchunhyang University Hospital Seoul, 59, Daesagwan-ro, Yongsan-gu, Seoul 04401, Korea

Full list of author information is available at the end of the article
}

Recently, a number of studies have suggested that remnant-preserving ACL reconstruction produces satisfactory clinical outcomes [1-3]. Theoretically, preserving ACL remnants might have advantages in terms of preserving proprioceptive mechanoreceptors, enhancing revascularization, reducing synovial fluid leakage into bone tunnels, and improving knee stability $[4,5]$. These advantages can result in excellent graft reinnervation, ligamentization, remodeling, and better clinical outcomes $[2,3]$.

The decision of whether to perform remnant-preserving or non-preserving ACL reconstruction is dictated by

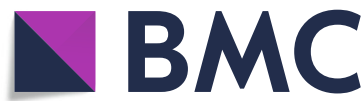

Part of Springer Nature (c) The Author(s). 2020 Open Access This article is distributed under the terms of the Creative Commons Attribution 4.0 International License (http://creativecommons.org/licenses/by/4.0/), which permits unrestricted use, distribution, and reproduction in any medium, provided you give appropriate credit to the original author(s) and the source, provide a link to the Creative Commons license, and indicate if changes were made. The Creative Commons Public Domain Dedication waiver (http://creativecommons.org/publicdomain/zero/1.0/) applies to the data made available in this article, unless otherwise stated. 
unique characteristics of the ACL remnant status. Remnant-preserving ACL reconstruction requires a more comprehensive and detailed diagnostic assessment of ACL injury patterns before and during surgery with an in-depth understanding of the anatomy of ACL insertion sites. Delicate debridement and bone tunnel placement are also important for reconstructing the ACL while preserving ACL remnants. Authors of some systematic reviews [6, 7] and meta-analyses $[8,9]$ have reported that patients in remnant-preserving ACL reconstruction groups do not have superior results to those in non-preserving groups. However, these systematic reviews and meta-analyses only reflect results of a small number of randomized controlled trials (RCTs).

The primary outcome of this meta-analysis was to analyze published literature to compare clinical outcomes of remnant-preserving versus non-preserving ACL reconstruction methods. The secondary outcome was to perform subgroup analyses of each clinical outcome from both prospective and observational studies. The hypothesis of this study was that remnant-preserving ACL reconstruction would have better clinical outcomes than non-preserving ACL reconstruction.

\section{Methods}

\section{Searching strategy}

Two researchers independently searched international electronic databases PubMed, Embase, and the Cochrane central database from January 1966 to December 2017 using the following keywords: anterior cruciate ligament, ACL, remnant, preservation, and stump. Search terms used in the PubMed search are presented in Table 1. Manual searches of all references listed in identified studies were also performed.

\section{Selection criteria}

Inclusion criteria were: [1] subjects, all adult patients who underwent arthroscopy-assisted ACL reconstruction regardless of sex or race; [2] intervention methods, arthroscopy-assisted ACL reconstruction and comparisons of clinical outcomes between remnant-preserving and non-preserving methods; [3] outcome parameters, KT-1000/2000 arthrometer (MEDmetric, San Diego, CA, USA), Rolimeter, pivot shift test, Lachman test results, Lysholm Knee Scoring Scale scores, International Knee Documentation Committee (IKDC) grades, IKDC subjective scores, cyclops lesion; and [4] study types, randomized controlled versus observational. Exclusion criteria were: [1] animal or cadaver studies; [2] comparisons not between remnant-preserving and nonpreserving method in arthroscopic ACL reconstruction; and [3] studies with $<1$-year of follow-up.
Table 1 Pubmed search strategy

\begin{tabular}{|c|c|}
\hline$\# 1$ & Anterior cruciate ligament [MeSH Terms] \\
\hline$\# 2$ & Anterior cruciate ligament [Title/abstract] \\
\hline$\# 3$ & Anterior cruciate ligaments [Title/abstract] \\
\hline$\# 4$ & ACL [Title/abstract] \\
\hline \#5 & $\# 1$ or \#2 or \#3 or \#4 \\
\hline \#6 & Reconstructive surgical procedures [MeSH Terms] \\
\hline \#7 & Reconstructive surgical procedures [Title/abstract] \\
\hline \#8 & Reconstructive surgical procedure [Title/abstract] \\
\hline \#9 & Reconstructive surgeries [Title/abstract] \\
\hline \#10 & Reconstructive surgery [Title/abstract] \\
\hline$\# 11$ & Reconstructive operation [Title/abstract] \\
\hline \#12 & $\# 6$ or \#7 or \#8 or \#9 or \#10 or \#11 \\
\hline \#13 & Arthroscopy [MeSH Terms] \\
\hline \#14 & Arthroscopy [Title/abstract] \\
\hline \#15 & $\# 13$ or \#14 \\
\hline \#16 & Joint instability [MeSH Terms] \\
\hline$\# 17$ & Joint instability [Title/abstract] \\
\hline \#18 & $\# 16$ or \#17 \\
\hline \#19 & Tendon transfer [MeSH Terms] \\
\hline \#20 & Tendon transfer [Title/abstract] \\
\hline \#21 & Transplantation [MeSH Terms] \\
\hline \#22 & Transplantation [Title/abstract] \\
\hline \#23 & Transplants [MeSH Terms] \\
\hline \#24 & Transplants [Title/abstract] \\
\hline \#25 & $\# 19$ or \#20 or \#21 or \#22 or \#23 or \#24 \\
\hline \#26 & Grafts [Title/abstract] \\
\hline \#27 & Augmentation [Title/abstract] \\
\hline \#28 & Single bundle [Title/abstract] \\
\hline \#29 & Double bundle [Title/abstract] \\
\hline \#30 & $\# 26$ or \#27 or \#28 \#29 \\
\hline \#31 & $\# 5$ or \#12 or \#15 or \#18 or \#25 or \#30 \\
\hline \#32 & Remnant [Title/abstract] \\
\hline \#33 & Stump [Title/abstract] \\
\hline \#34 & Minimal debridement [Title/abstract] \\
\hline \#35 & ACL tissue [Title/abstract] \\
\hline \#36 & $\# 32$ or \#33 or \#34 or \#35 \\
\hline \#37 & $\# 31$ and \#36 \\
\hline
\end{tabular}

\section{Literature selection}

Two researchers independently selected all articles following the above-mentioned selection criteria while assessing qualities of selected articles. Any disagreement was resolved through discussion with the corresponding researcher. The Physiotherapy Evidence Database (PEDro) scale was used for RCTs. The scale comprised 11 items based on the Delphi list to assess the methodological quality of each article. 
Each item was scored yes or no. Scoring system on the basis of Newcastle-Ottawa Scale (NOS) was used to assess the quality of included observational studies.

\section{Data extraction}

Using the same format, two researchers independently extracted data from articles, compared data, and repeated extractions and comparisons for items with inconsistencies. Specifically, two researchers extracted the following information from each study: first author, year of publication, country where the study was performed, study design, number of cases and controls, age, sex, follow-up period, type of graft, number of bundles, KT1000/2000 arthrometer measurement, Rolimeter, pivot shift test, Lachman test result, Lysholm scores, IKDC grade and subjective scores and cyclops lesion, relative risk (RRs) or standardized incidence ratio (SIRs) with 95\% confidence intervals (CIs), and variables used in multivariate adjustments (Tables 2 and 3). To obtain the omitted data, we e-mailed some authors [5, 10-19]. The meta-analysis was conducted in accordance with PRISMA (Preferred Reporting Items for Systematic Review and Meta-Analysis) guidelines.

\section{Statistical methods}

The meta-analysis was conducted using $R$ version 3.1.2 "metafor" and "meta" packages). For all comparisons, a random-effects model was used. Odds ratio (OR) and 95\% confidence intervals (CI) were presented. OR was used to estimate the overall effect size for binary outcome. Standardized mean difference (SMD) or mean difference measure was used to calculate the overall effect size for continuous outcome. Values of SMD or MD and 95\% CI were presented. Using the measure for summary statistics of continuous variable, whether the same measurements were used or not was determined. The heterogeneity of involved studies was tested with a level of significance of $\alpha=0.10$ to calculate the heterogeneity index $\mathrm{I}^{2}$. The estimate of $\mathrm{I}^{2} \leq 60 \%$ was considered as low statistical heterogeneity between studies. When heterogeneity was presented, a subgroup analysis and sensitivity analysis were used to find out which study was causing the problem. Subgroup analyses were undertaken to evaluate the type of study design (RCT or observational study) in the primary meta-analysis estimate. The sensitivity analysis was performed to evaluate for the cause of heterogeneity by using results obtained when each study was excluded from all studies used in overall results. To determine the publication bias, Begg's test and funnel plot (Fig. 1) were used. There was no evidence of significant publication bias $(P=$ 0.146 for knee laxity; $P=0.634$ for Pivot shift test; $P=0.649$ for Lachman test; $P=0.203$ for Lysholm scores; $P=0.261$ for IKDC grade; $P=0.328$ for IKDC subjective scores; and $P=0.480$ for Cyclops lesion).

Table 2 Description of included trials: Demographics and operation overview

\begin{tabular}{|c|c|c|c|c|c|c|c|c|c|c|c|c|}
\hline \multirow[t]{2}{*}{ Author } & \multirow[t]{2}{*}{ Year } & \multirow[t]{2}{*}{ Country } & \multirow{2}{*}{$\begin{array}{l}\text { Sample } \\
\text { Size (P/S) }\end{array}$} & \multirow{2}{*}{$\begin{array}{l}\text { Mean } \\
\text { Age } \\
(\mathrm{P} / \mathrm{S})\end{array}$} & \multicolumn{2}{|c|}{ Sex ratio (M/F) } & \multirow{2}{*}{$\begin{array}{l}\text { Follow-up, } \\
\text { Months } \\
\text { (P/S) }\end{array}$} & \multirow{2}{*}{$\begin{array}{l}\text { Type of } \\
\text { graft }\end{array}$} & \multirow{2}{*}{$\begin{array}{l}\text { No. of } \\
\text { Bundles }\end{array}$} & \multirow{2}{*}{$\begin{array}{l}\text { Surgical } \\
\text { technique }\end{array}$} & \multirow{2}{*}{$\begin{array}{l}\text { Journal } \\
\text { name }\end{array}$} & \multirow{2}{*}{$\begin{array}{l}\text { Level of } \\
\text { Evidenc }\end{array}$} \\
\hline & & & & & $\bar{P}$ & $\mathrm{~S}$ & & & & & & \\
\hline \multicolumn{13}{|l|}{$\overline{\mathrm{RCT}}$} \\
\hline Gohil, et al. [10] & 2007 & Australia & $24 / 25$ & $36 / 31$ & $14 / 10$ & $13 / 12$ & $12 / 12$ & autograft & SB & Transtibial & JBJS (Br) & Level I \\
\hline Hong, et al. [11] & 2012 & China & $45 / 45$ & $34 / 28$ & $33 / 12$ & $34 / 11$ & $26 / 26$ & allograft & SB & Transtibial & AJSM & Level I \\
\hline Mohtadi, et al. [12] & 2012 & Canada & $43 / 43$ & $20 / 30$ & $19 / 24$ & $24 / 19$ & $12 / 12$ & autograft & SB & Transtibial & CJSM & Level I \\
\hline \multirow[t]{3}{*}{ Pujol, et al. [13] } & 2012 & France & $29 / 25$ & $31 / 29$ & $16 / 13$ & $17 / 8$ & $12 / 12$ & autograft & SB & Out-side in & OTSR & Level I \\
\hline & & & & & & & & & & AM portal & & \\
\hline & & & & & & & & & & Transtibial & & \\
\hline Zhang, et al. [5] & 2014 & China & $27 / 24$ & $24 / 25$ & $19 / 4$ & $21 / 5$ & $24 / 25$ & autograft & SB & Transtibial & KSSTA & Level I \\
\hline \multicolumn{13}{|l|}{ Observation study } \\
\hline Qi, et al. [14] & 2010 & China & $37 / 59$ & $24 / 28$ & $26 / 11$ & $35 / 24$ & $15 / 15$ & allograft & SB & Out-side in & CJRRS & Level II \\
\hline Park, et al. [15] & 2012 & South Korea & $55 / 45$ & $30 / 32$ & $45 / 10$ & $40 / 5$ & $34 / 31$ & $\begin{array}{l}\text { autograft, } \\
\text { allograft }\end{array}$ & $\mathrm{SB}, \mathrm{DB}$ & Transtibial & Arthroscopy & Level IV \\
\hline Naylor, et al. [16] & 2013 & Canada & $45 / 45$ & $30 / 30$ & $21 / 24$ & $26 / 19$ & $12 / 12$ & autograft & SB & Transtibial & SOST & Level II \\
\hline Takazawa, et al. [17] & 2013 & Japan & $85 / 98$ & $24 / 26$ & \multicolumn{2}{|c|}{$124 / 59$} & $33 / 31$ & autograft & SB & Transtibial & OJSM & Level III \\
\hline Chen, et al. [18] & 2015 & China & $38 / 37$ & $29 / 27$ & $27 / 11$ & $25 / 12$ & $12 / 12$ & autograft & SB & Transtibial & CJTER & Level III \\
\hline Kondo, et al. [19] & 2015 & Japan & $81 / 98$ & $29 / 30$ & $44 / 37$ & $54 / 44$ & $14 / 14$ & autograft & $\mathrm{DB}$ & AM portal & AJSM & Level ॥ \\
\hline
\end{tabular}

$P$ Preserved group, $S$ Standard group, $M$ Male, $F$ Female, SB Single bundle, DB Double bundle, AM Anteromedial, JBJS (Br) Journal of Bone and Joint Surgery (British), AJSM The American journal of sports medicine, CJSM Clinical Jounral of Sport Medicine, OTSR Orthopaedics \& traumatology, surgery \& research, KSSTA Knee Surgery, Sports Traumatology, Arthroscopy, CJRRS Chinese journal of reparative and reconstructive surgery, SOST Sport-Orthopadie - Sport-Traumatologie, OJSM Orthopaedic Journal of Sports Medicine, CJTER Chinese Journal of Tissue Engineering Research 
Table 3 Description of included trials: Method of Evaluation

\begin{tabular}{|c|c|c|c|c|c|c|c|c|c|c|}
\hline \multirow[t]{3}{*}{ Author } & \multicolumn{3}{|l|}{ Stability } & \multirow{3}{*}{$\begin{array}{l}\text { Pivot shift } \\
\text { test }\end{array}$} & \multirow{3}{*}{$\begin{array}{l}\text { Lachman } \\
\text { test }\end{array}$} & \multirow{3}{*}{$\begin{array}{l}\text { Lysholm } \\
\text { test }\end{array}$} & \multirow{3}{*}{$\begin{array}{l}\text { IKDC } \\
\text { grade }\end{array}$} & \multirow{3}{*}{$\begin{array}{l}\text { IKDC subjective } \\
\text { score }\end{array}$} & \multirow{2}{*}{\multicolumn{2}{|c|}{$\frac{\text { Complication }}{\text { Cyclops lesion }}$}} \\
\hline & \multirow[t]{2}{*}{ KT-1000 } & \multirow[t]{2}{*}{ KT-2000 } & \multirow[t]{2}{*}{ Rolimeter } & & & & & & & \\
\hline & & & & & & & & & $\overline{M R I}$ & Second look arthroscopy \\
\hline \multicolumn{11}{|l|}{$\mathrm{RCT}$} \\
\hline Gohil, et al. [10] & O & & & & & & & $\mathrm{O}$ & O & \\
\hline Hong, et al. [11] & O & & & O & $\mathrm{O}$ & O & O & & & O \\
\hline Mohtadi, et al. [12] & $\mathrm{O}$ & & & O & & & & & & \\
\hline Pujol, et al. [13] & & & $\mathrm{O}$ & $\mathrm{O}$ & $\mathrm{O}$ & O & O & $\mathrm{O}$ & & $\mathrm{O}$ \\
\hline Zhang, et al. [5] & & $\mathrm{O}$ & & & & O & & & & \\
\hline \multicolumn{11}{|l|}{ Observation study } \\
\hline Qi, et al. [14] & & $\mathrm{O}$ & & & & $\mathrm{O}$ & & $\mathrm{O}$ & & \\
\hline Park, et al. [15] & $\mathrm{O}$ & & & $\mathrm{O}$ & $\mathrm{O}$ & $\mathrm{O}$ & & $\mathrm{O}$ & & \\
\hline Naylor, et al. [16] & & $\mathrm{O}$ & & $\mathrm{O}$ & $\mathrm{O}$ & & $\mathrm{O}$ & $\mathrm{O}$ & & \\
\hline Takazawa, et al. [17] & & $\mathrm{O}$ & & $\mathrm{O}$ & & & & & & \\
\hline Chen, et al. [18] & & $\mathrm{O}$ & & & & $\mathrm{O}$ & & $\mathrm{O}$ & & \\
\hline Kondo, et al. [19] & & $\mathrm{O}$ & & $\mathrm{O}$ & & $\mathrm{O}$ & & & & O \\
\hline
\end{tabular}

IKDC International Knee Documentation Committee, MRI Magnetic resonance imaging

\section{Results}

\section{Search results and study characteristics}

Through our literature search, 552 potentially relevant studies were identified. After removing duplicate articles (19), 117 were identified by screening titles and abstracts. Finally, five RCTs [5, 10-13] and six observational studies [14-19] were included in this meta-analysis with subgroup analysis. A summary of the review process is presented in Fig. 2.

The total sample size was 1053 patients. In RCTs, 168 patients in the remnant-preserving method group and 162 patients in the non-preserving method group. In observational studies, 341 patients in the remnantpreserving method group and 382 patients in the nonpreserving method group. All included studies used either autograft or allograft with different graft fixation techniques. And follow-up duration of each studies were more than 12 months. Table 2 summarized demographics and surgical details of included studies in this meta-analysis and Table 3 summarized outcome parameters of clinical evaluation of included study in this meta-analysis.

Moderate inter-rater reliability (intraclass correlation coefficients $(\mathrm{ICC})=0.68,95 \% \mathrm{CI}: 0.57$ to $0.76 \%$ ) was
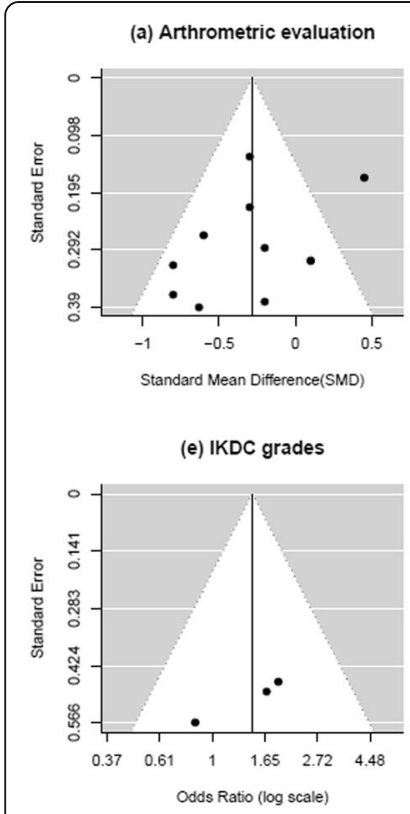

(b) Negative Pivot shift

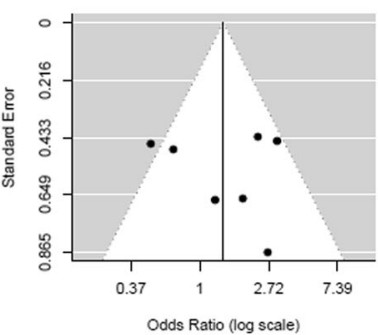

(f) IKDC subjective scores

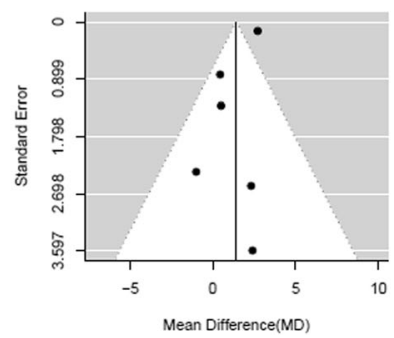

(c) Negative Lachman test

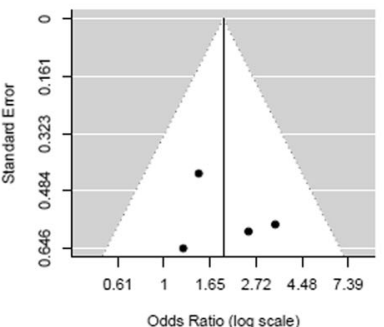

(g) Cyclops lesion

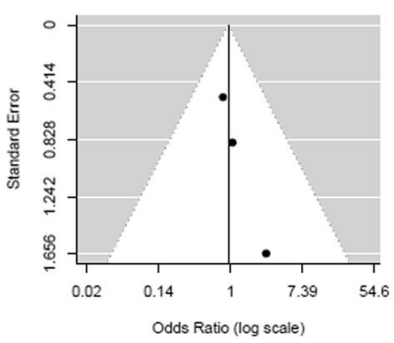

(d) Lysholm scores

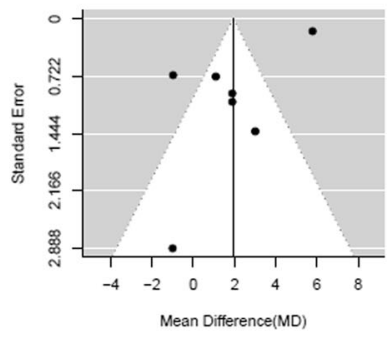

Fig. 1 Funnel plot for publication bias 
552 Records identified Through database searching

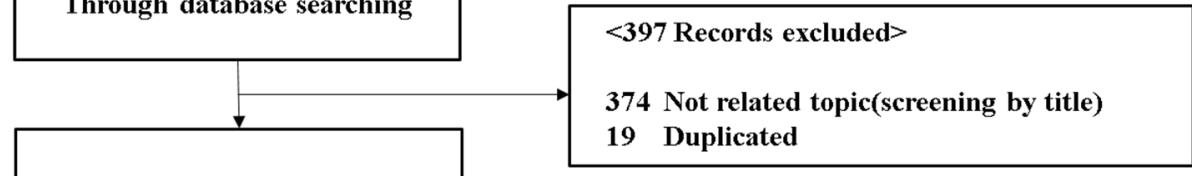

155 Records

For further assessment

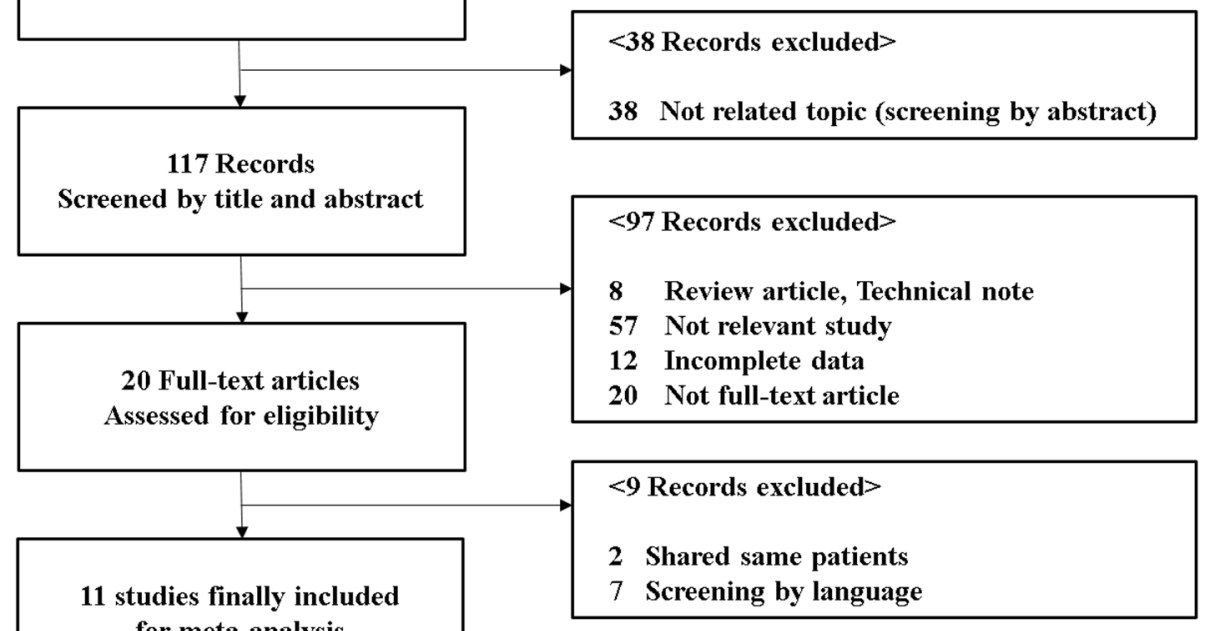

for meta-analysis

Fig. 2 Flowchart of article selection process

demonstrated by the PEDro score on RCTs. Trials with scores $\geq 6$ were considered to be of high quality and all RCTs showed scoring of high quality (Table 4). Observational study with scores $\geq 7$ were considered to be of high quality and all observational studies showed scoring of high quality (Table 5).

\section{Arthrometric evaluation (side- to- side difference)}

Five RCTs [5, 10-13] and five observational studies [1519] reported arthrometric evaluation (KT-1000, KT-2000, Rolimeter, magnitude of side-to-side difference). A total of 472 patients in remnant-preserving groups and 485 patients in non-preserving groups were analyzed. A random-effects model was used to calculate summary statistics and standard mean differences to estimate overall effect sizes because different authors used different measurement units for each study. Results showed significant differences between remnant-preserving and remnant non-preserving groups across studies (SMD: -0.28, 95\% CI: -0.55 to $-0.02, P=0.038)$. However, there was significant heterogeneity $\left(P=0.002, \mathrm{I}^{2}=63.66 \%\right)$. When subgroup analysis was performed by study design, effect magnitudes and statistical significance changed in observational studies (SMD: $-0.34,95 \% \mathrm{CI}:-0.53$ to $-0.14, P=0.001)$. There was no heterogeneity $\left(P=0.26\right.$ and $\mathrm{I}^{2}=0.01 \%$; Fig. 3$)$. In
Table 4 PEDro critical appraisal tool results of 5 Randomized Controlled Trials

\begin{tabular}{|c|c|c|c|c|c|c|c|c|c|c|c|c|c|}
\hline \multirow[t]{2}{*}{ Study } & & \multicolumn{11}{|c|}{ PEDro Criteria } & \multirow[t]{2}{*}{ Tota } \\
\hline & & 1 & 2 & 3 & 4 & 5 & 6 & 7 & 8 & 9 & 10 & $\overline{11}$ & \\
\hline \multicolumn{14}{|l|}{$\mathrm{RCT}$} \\
\hline Gohil, et al. [10] & 2007 & $N$ & Y & Y & Y & Y & $N$ & Y & Y & Y & Y & Y & 9 \\
\hline Hong, et al. [11] & 2012 & Y & Y & Y & Y & Y & $\mathrm{N}$ & $\mathrm{N}$ & Y & Y & Y & Y & 8 \\
\hline Mohtadi., et al. [12] & 2012 & Y & Y & $N$ & Y & Y & $\mathrm{N}$ & $\mathrm{N}$ & Y & Y & Y & Y & 7 \\
\hline Pujol, et al. [13] & 2012 & Y & Y & $\mathrm{N}$ & Y & Y & $\mathrm{N}$ & N & Y & Y & Y & Y & 7 \\
\hline Zhang, et al. [5] & 2014 & Y & Y & $\mathrm{N}$ & Y & Y & $\mathrm{N}$ & Y & Y & Y & Y & Y & 8 \\
\hline
\end{tabular}

PEDro Physiotherapy Evidence Database scale, RCT Randomized Controlled Trial, $Y$ Yes, $N$ No

Criteria: 1 . eligibility criteria were specified; 2 . subjects were randomly allocated to groups (in a crossover study, subjects were randomly allocated an order in which treatments were received); 3 . allocation was concealed; 4 . the groups were similar at baseline regarding the most important prognostic indicators; 5 . there was blinding of all subjects; 6 . there was blinding of all therapists who administered the therapy; 7 . there was blinding of all assessors who measured at least one key outcome; 8 . measures of at least one key outcome were obtained from more than $85 \%$ of the subjects initially allocated to groups; 9 . all subjects for whom outcome measures were available received the treatment or control condition as allocated or, where this was not the case, data for at least one key outcome was analysed by "intention to treat"; 10. the results of between-group statistical comparisons are reported for at least one key outcome; 11 . the study provides both point measures and measures of variability for at least one key outcome 
Table 5 Newcastle-Ottawa scale for assessing the quality of 6 observational studies

\begin{tabular}{|c|c|c|c|c|c|c|c|c|c|c|}
\hline & & & & & & & & & Total score & \\
\hline & 1 & 2 & 3 & 4 & 5 & 6 & 7 & 8 & & \\
\hline Qi, et al. [14] & 2010 & $\star$ & $\star$ & $\star$ & $\star$ & $\star$ & $\star$ & $\star$ & & 7 \\
\hline Park, et al. [15] & 2012 & $\star$ & $\star$ & $\star$ & $\star$ & $\star \star$ & $\star$ & $\star$ & $\star$ & 9 \\
\hline Naylor, et al. [16] & 2013 & $\star$ & $\star$ & $\star$ & $\star$ & $\star \star$ & $\star$ & $\star$ & & 8 \\
\hline Takazawa, et al. [17] & 2013 & $\star$ & $\star$ & $\star$ & $\star$ & $\star$ & $\star$ & $\star$ & $\star$ & 8 \\
\hline Chen, et al [18] & 2015 & $\star$ & $\star$ & $\star$ & $\star$ & $\star$ & $\star$ & $\star$ & & 7 \\
\hline Kondo, et al. [19] & 2015 & $\star$ & $\star$ & $\star$ & $\star$ & $\star \star$ & $\star$ & $\star$ & & 8 \\
\hline
\end{tabular}

Criteria: 1. Representativeness of the exposed cohort; 2 . Selection of the non-exposed cohort; 3. Ascertainment of exposure; 4 . Outcome not present at the start of the study; 5 . Comparability; 6 . Assessment of outcome, 7. Length of follow-up (study with follow-up time $>2$ years was assigned one star); 8 . Adequacy of follow-up (study with follow-up rate $>80 \%$ was assigned one star)

contrast, there was still significant heterogeneity between studies $\left(P=0.01, \mathrm{I}^{2}=68.69 \%\right)$ among RCTs, although results of the pooled estimations were not statistically significant (SMD: $-0.24,95 \% \mathrm{CI}$ : -0.69 to $0.20, P=0.28$; Fig. 4). To address the heterogeneity that remained among the RCT subgroup, a sensitivity analysis was conducted by year. The study by Gohil et al. [10] was regarded as an outlier study because the calculated summary statistics (SMD: $-0.39,95 \%$ CI: -0.66 to $-0.13, P=0.003$ ) showed a big difference except for the effect of the study. The heterogeneity disappeared to $0 \%$ of $\mathrm{I}^{2}$ after excluding that study (Fig. 4).

\section{Pivot shift test}

Grade 0 as was defined as negative pivot shift. Otherwise, it was defined as positive pivot shift. Pivot shift tests were conducted with three RCTs [11-13] and four observational studies [15-17, 19], analyzing a total of 383 patients in the remnant-preserving group and 399 in the remnant nonpreserving group. A random-effects model was used to calculate summary statistics. No significant difference was found between the two groups (OR: 1.41, 95\% CI: 0.78 to 2.53, $P=0.25)$. There was a low statistical heterogeneity among studies $\left(P=0.05, \mathrm{I}^{2}=53.24 \%\right)$. Subgroup analyses were then performed by study design. Analysis of three RCTs showed no significant differences between the two groups (OR: $1.15,95 \% \mathrm{CI}: 0.38$ to $3.44, P=0.80$ ). There was a low statistical heterogeneity among studies $\left(P=0.10, \mathrm{I}^{2}=\right.$ $55.61 \%)$. Analysis of four observational studies showed the same results: no significant difference between the two groups (OR: $1.63,95 \% \mathrm{CI}$ : 0.81 to $3.28, P=0.17$ ) and low statistical heterogeneity among studies $\left(\mathrm{P}=0.10, \mathrm{I}^{2}=\right.$ 52.28\%; Fig. 5).

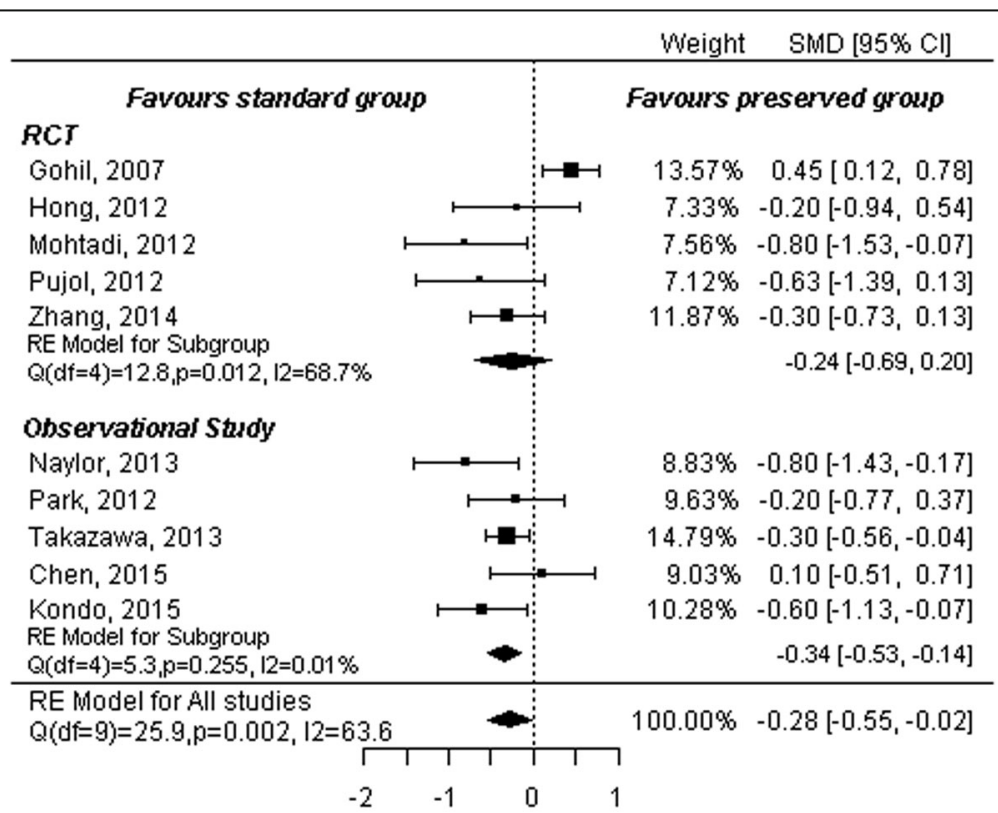

(a) Arthrometric evaluation

Fig. 3 Forest plot of meta-analysis: Arthrometric evaluation 


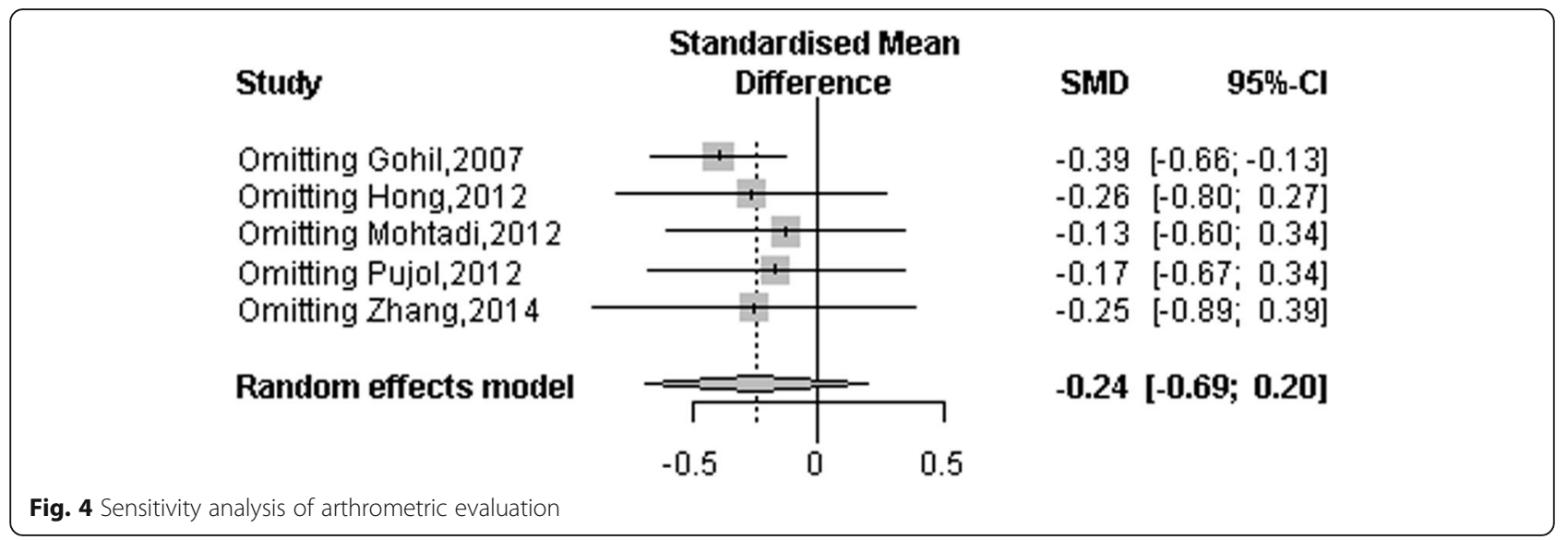

\section{Lachman test}

Two RCTs $[11,13]$ and two observational studies $[15,16]$ reported Lachman test results. A total of 174 patients in the remnant-preserving group and 160 patients in the remnant non-preserving group were analyzed. A randomeffects model was used to calculate summary statistics. Results showed significant differences between the two groups (OR: $1.91,95 \% \mathrm{CI}: 1.12$ to $3.25, P=0.02$ ) and no heterogeneity among studies $\left(P=0.58, \mathrm{I}^{2}=0.00 \%\right)$. Subgroup analyses were then performed by study design. Analysis of two RCTs showed no significant differences between the two groups (OR: $2.11,95 \%$ CI: 0.80 to 5.60 , $P=0.13)$ and low statistical heterogeneity among studies $\left(P=0.25, \mathrm{I}^{2}=24.56 \%\right)$. Analysis of two observational studies showed the same results: no significant differences between the two groups (OR: $1.76,95 \%$ CI: 0.88 to 3.52 , $P=0.11)$ and no heterogeneity among studies $(P=0.47$, $\mathrm{I}^{2}=0.00 \%$; Fig. 6).

\section{Lysholm scores}

Three RCTs $[5,11,13]$ and four observational studies [14, $15,18,19]$ reported Lysholm knee scoring scale scores for a total of 312 patients in the remnant-preserving group and 333 in the remnant non-preserving group. A randomeffects model was used to calculate summary statistics. Results showed statistically significant differences between the two groups (MD: 1.94, 95\% CI: 0.07 to $3.81, P=0.042$ ) and statistical heterogeneity among studies $\left(P<0.001, \mathrm{I}^{2}=\right.$ 91.01\%). Subgroup analyses were performed by study design. Analysis of three RCTs showed no significant

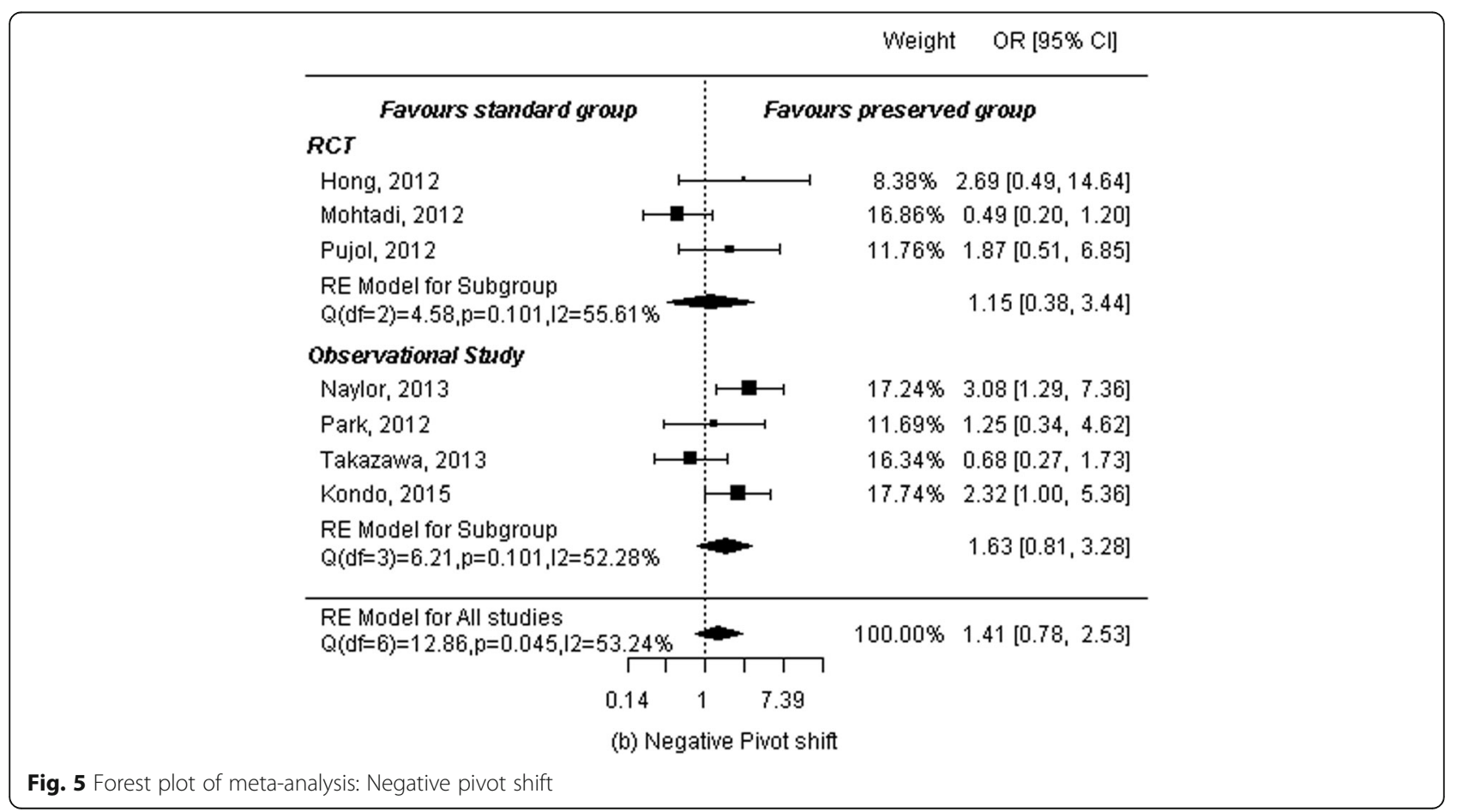




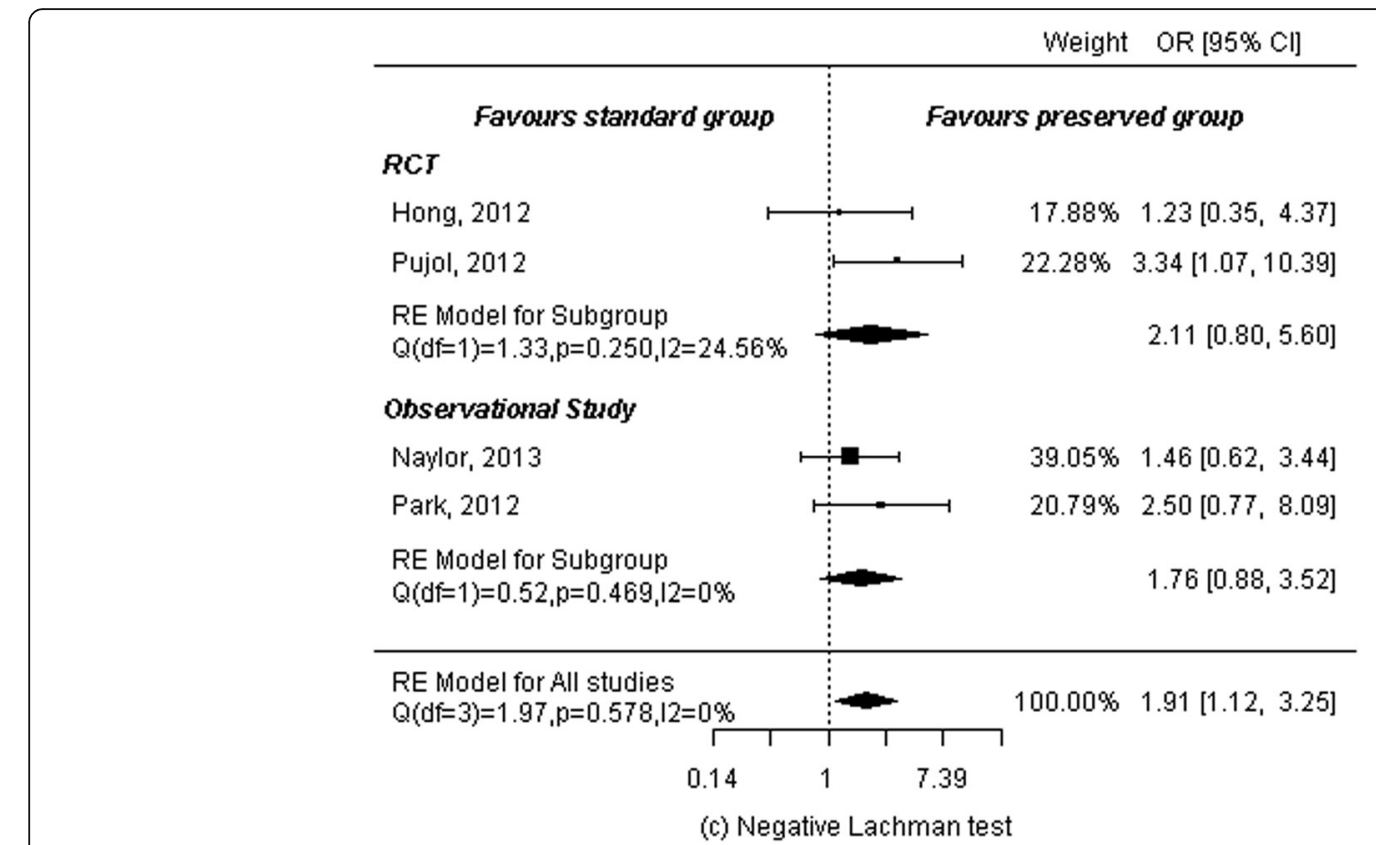

Fig. 6 Forest plot of meta-analysis: Negative Lachmann test

differences between the two groups (MD: 1.10, 95\% CI: 1.30 to $3.50, P=0.37)$ and significant heterogeneity $(P=$ $0.01, \mathrm{I}^{2}=76.42 \%$ ). Analysis of four observational studies showed the same results: no significant differences between the two groups (MD: $2.48,95 \% \mathrm{CI}:-0.26$ to $5.23, P=0.08$ ) and significant heterogeneity $\left(\mathrm{P}<0.001, \mathrm{I}^{2}=92.63 \%\right.$; Fig. 7).

\section{IKDC grade}

Two RCTs [11, 13] and one observational study [16] included IKDC grades for a total of 119 patients in the remnant-preserving group and 115 in the remnant non-preserving group. A random-effects model was used to calculate summary statistics. Results showed no

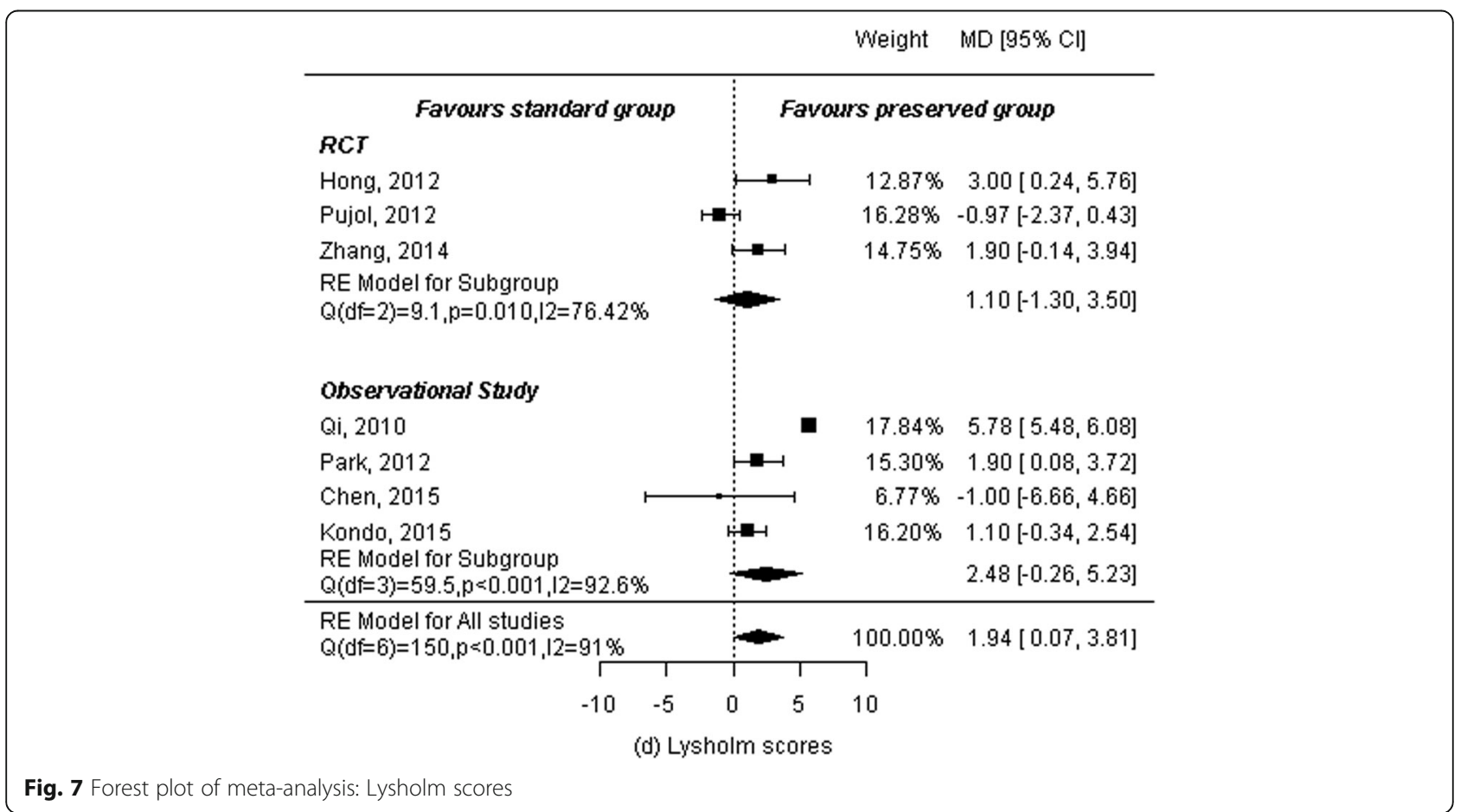


significant difference between the two groups (OR: 1.47, 95\% CI: 0.83 to $2.58, P=0.19$ ) and no heterogeneity among studies $\left(P=0.53, \mathrm{I}^{2}=0.00 \%\right)$. Subgroup analysis was performed according to study design. Analysis of two RCTs showed no significant differences between the two groups (OR: $1.25,95 \% \mathrm{CI}$ : 0.61 to $2.59, P=0.54$ ) and no heterogeneity among studies $\left(\mathrm{P}=0.37, \mathrm{I}^{2}=0.00 \%\right.$; Fig. 8).

\section{IKDC subjective scores}

Two RCTs $[10,13]$ and four observational studies [14$16,18]$ reported IKDC subjective scores for a total of 228 patients in the remnant-preserving group and 236 in the remnant non-preserving group. A random-effects model was used to calculate summary statistics. There was statistically significant difference between the two groups (MD: $1.42,95 \% \mathrm{CI}: 0.01$ to $2.83, P=0.048$ ). There was a low statistical heterogeneity among studies $(P=$ $0.03, \mathrm{I}^{2}=55.22 \%$ ). Subgroup analyses were performed by study design. Analysis of two RCTs showed no significant differences between the two groups (MD: 0.54, 95\% CI: -1.05 to $2.12, P=0.50)$. The heterogeneity was resolved $\left(P=0.60, \mathrm{I}^{2}=0.00 \%\right)$. Analysis of four observational studies showed the same results: no significant differences between the two groups (MD: 1.71, 95\% CI: - 0.02 to $3.43, P=0.053)$ and low statistical heterogeneity among studies $\left(P=0.15, \mathrm{I}^{2}=45.92 \%\right.$; Fig. 9$)$.

\section{Cyclops lesion}

Two RCTs [11, 13] and one observational study [19] reported cyclops lesion among a total of 155 patients in the remnant-preserving group and 168 in the remnant non-preserving group. A random-effects model was used to calculate summary statistics. There was no significant difference between the two groups (OR: 0.94, 95\% CI: 0.40 to $2.20, P=0.89)$. There was no heterogeneity among studies $\left(P=0.78, \mathrm{I}^{2}=0.00 \%\right)$. Subgroup analyses were performed by study design. Analysis of three RCTs showed no significant difference between the two groups (OR: $1.28,95 \%$ CI: 0.29 to $5.64, P=0.74$ ). There was no heterogeneity among the studies either $\left(P=0.62, \mathrm{I}^{2}=\right.$ $0.00)$. Additionally, one observational study showed no significant difference between the two groups (MD: 0.81, 95\% CI: 0.29 to $2.28, P=0.69$; Fig. 10 ).

\section{Discussion}

Investigation to reveal the value of the remnant preservation in ACL reconstruction is important in the field of sports medicine. Reflecting this, systematic review $[6,7]$ and meta-analysis $[8,9]$ on this topic have been published over the past years. The present meta-analysis investigated clinical outcome differences including mechanical stability using arthrometric evaluation, functional evaluation, and complications between remnant preserving and non-preserving method for primary arthroscopic ACL reconstruction.

The key finding of the current meta-analysis that included five RCTs and six observational studies was that the remnant-preserving method showed a statistically significant difference compared to the non-preserving method with respect to arthrometric evaluation (side-toside difference). Results of subgroup analyses also demonstrated statistically significant difference between the two groups without heterogeneity. Lachman test, Lysholm scores, and IKDC subjective scores showed statistical difference in meta-analysis, but showed no

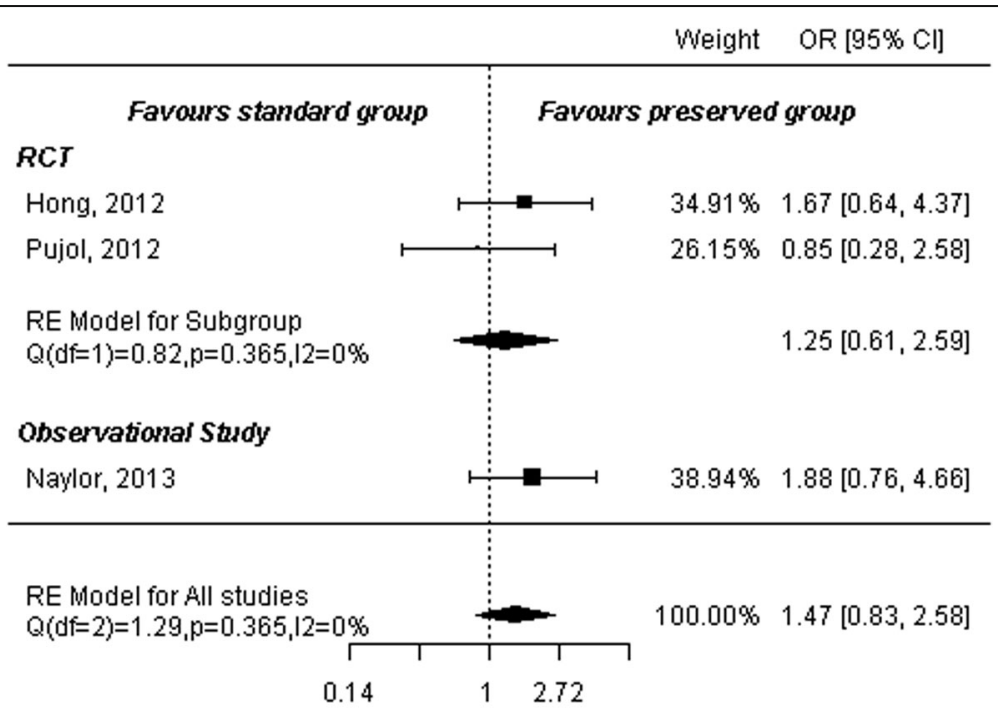

(e) IKDC grades

Fig. 8 Forest plot of meta-analysis: IKDC grades 


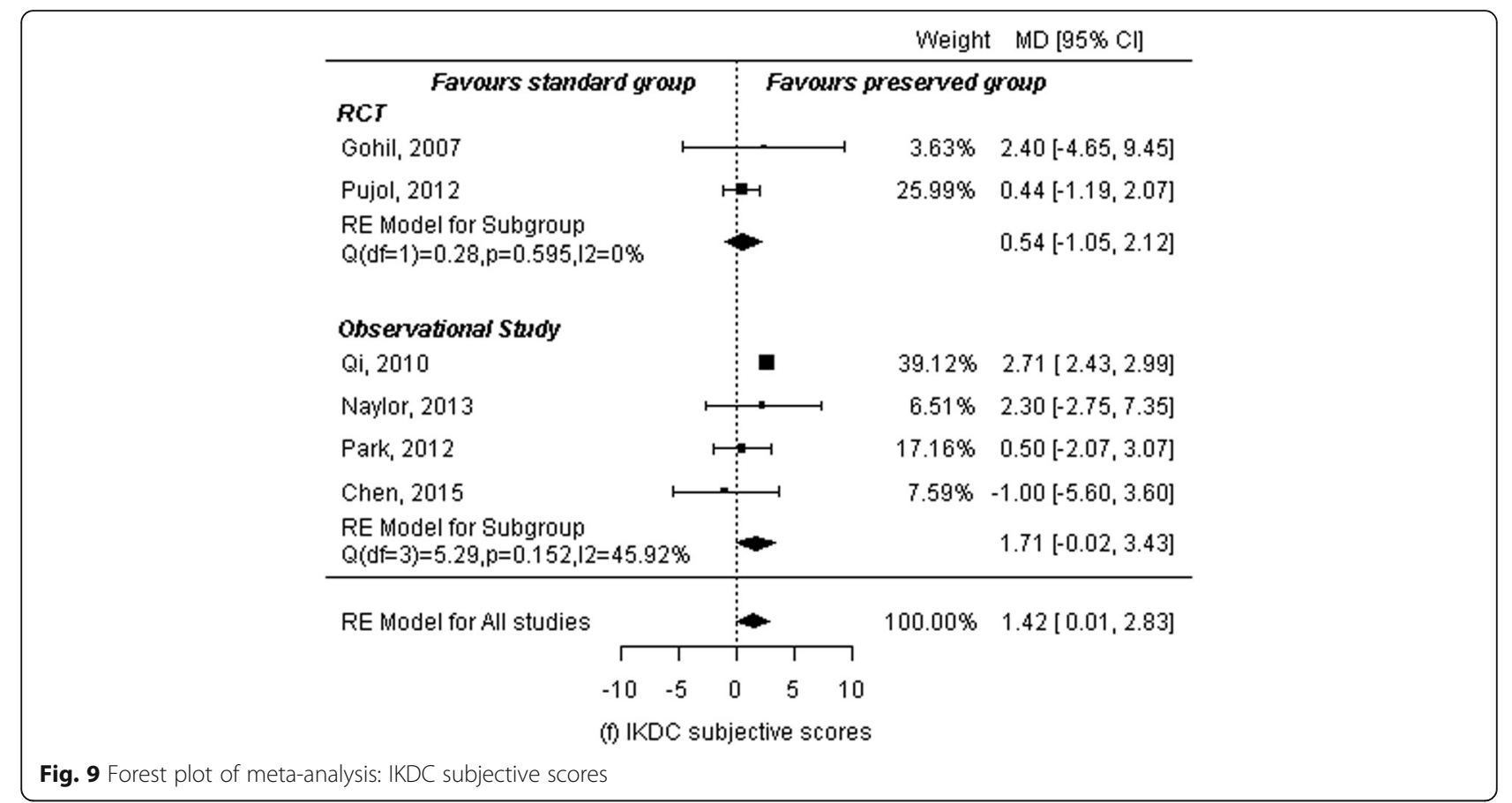

statistical difference in subgroup analysis in each outcome parameter. Remaining outcome parameters including pivot shift test, IKDC grades, incidence of cyclops lesion showed no statistically differences in metaanalysis or subgroup analysis.

One of the goals of ACL reconstruction is to restore biomechanically stable joint. From this viewpoint, many investigators have made efforts to improve clinical results. In this respect, remnant preserving method is one of considerable efforts for primary ACL reconstruction.
After the report of arthroscopic remnant-preserving ACL reconstruction by Lee et al. [4], many studies have reported remnant-preserving techniques and their clinical outcomes. Lee et al. [20] and Ahn et al. [21] have reported good clinical outcomes after remnant-preserving ACL reconstruction. Some clinical studies [22, 23] have revealed that the remnant preserving method in ACL reconstruction can influence knee joint stability. Kondo et al. [19] have reported that the remnant-preserving method shows significantly better outcome in terms of

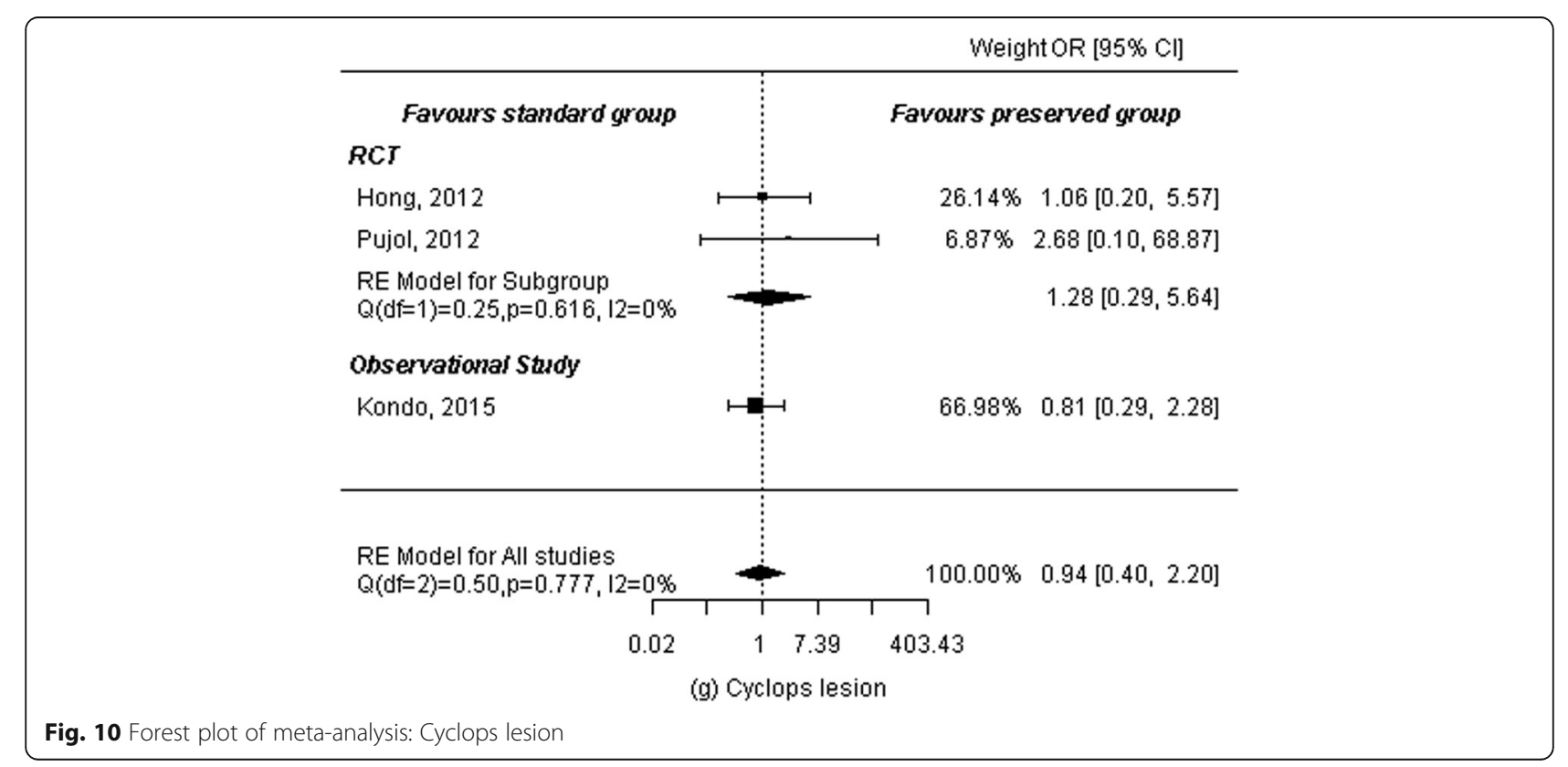


mechanical stability and arthroscopic evaluation than the non-preserving method after anatomic doublebundle arthroscopic ACL reconstruction. Kitamura et al. [24] have evaluated intraoperative 3-dimensional kinematics using an electromagnetic sensor system and demonstrated that the remnant-preserving anatomic doublebundle ACL reconstruction appears to improve the control of pivot-shift laxity at a minimum of 12 months after surgery. Kim et al. [25] have reported that the mean postoperative arthrometric evaluation (side-to-side difference) is $1.67 \mathrm{~mm}$ on $\mathrm{KT}-2000$ for those who have undergone remnant-preserving double bundle ACL reconstruction. Adachi et al. [26] have reported that the mean postoperative arthrometric evaluation (side-to-side difference) in the remnant preserving group is $0.7 \mathrm{~mm}$ versus $1.8 \mathrm{~mm}$ in the non-preserving group $(P<0.05)$. In this meta-analysis, statistical results of arthrometric evaluation (side-to-side difference) were comparable to those of previous studies. Based on such results, the remnant-preserving method in ACL reconstruction may preserve a portion of blood vessels from the tibial attachment site which may accelerate revascularization of the graft, resulting in early restoration of mechanical properties of the graft. This might be one of possible reasons for better stability. There is a view that preserving remnant tissue may lead to complications such as cyclops lesion [27], also known as localized anterior arthrofibrosis with extension limitation. The incidence of a cyclops lesion related to ACL reconstruction has been reported to range from 2 to $47 \%$ [21, 28]. Many studies have suggested that remnant-preserving method does not increase the incidence of cyclops lesion [10, 11, 13, 19]. Results of our meta-analysis showed no statistically significant difference in the incidence of cyclops lesion between remnant-preserving method and nonpreserving method $(P>0.05)$.

However, actual effectiveness of remnant-preserving method is still inconsistent. It is currently unclear whether there is a definitive clinical relevance or advantage over non-preserving method during arthroscopic ACL reconstruction. Although this meta-analysis results showed statistically significant difference in terms of arthrometric evaluation between the two groups, interpretation of this result should have limited clinical relevance because magnitude of the differences was not large enough (0.1-1.4 $\mathrm{mm})$, the arthrometer measures anterior knee laxity in 1 $\mathrm{mm}$ increments of precision and IKDC considers a sideto-side difference as normal value up to $2 \mathrm{~mm}[29,30]$.

Results of Lachman test, Lysholm scores, and IKDC subjective scores also demonstrated statistically minor differences. However, these minor differences did not reflect the clinical relevance. They were not large enough to distinguish clinical differences. Statistically, the calculated summary statistics, including each subgroup and all results of the study, showed different results. In addition, the $95 \% \mathrm{CI}$ of overall summary statistics showed a slight deviation from the boundary. Point estimates were statistically significant. Therefore, a pattern of increasing statistical significance may show by increasing the number of samples. Thus, more research is needed than to conclude that it is significant.

A number of studies [11,31] have compared clinical outcomes of remnant-preserving and non-preserving methods and found no statistically significant differences between the two groups. Ma et al. [8] have found significant differences in favor of remnant-preserving method for Lysholm scores, arthrometer measurements, and tibial tunnel enlargements. They reported no significant differences between remnant-preserving and nonpreserving methods with respect to IKDC grades and scores, Lachman test results, pivot shift test results, range of motion, and incidence of cyclops lesion. Tie et al. [9] have performed a meta-analysis of RCTs and found no significant difference between groups for KT arthrometer, negative Lachman test scores, or pivot shift test results. By functional outcomes, the authors found no significant differences in IKDC scores/grades or Lysholm scores. The percentage of tibial tunnel enlargement in the remnant-preserving group was significantly lower, although there was no significant difference in the incidence of cyclops lesion. However, their meta-analysis had the following errors. The mixture of ACL partial tears RCTs with remnant- preserving RCTs (remnantpreserving vs. non-preserving ACL reconstruction) compared two different situations which could cause significant bias. Therefore, we considered ACL partial tear study should be excluded. Furthermore, randomized controlled trials in this meta-analysis have unclear quality of remnant. They have a risk of bias because the method of blinding is not reported.

Our meta-analysis and subgroup analysis have some limitations that should be taken into account. First, although we assessed the quality of included observational studies using quality assessment tool (NOS) and found that all of them had good quality, observational study itself has a lower level of evidence than RCT. Second, there was heterogeneity between studies with regard to patient characteristics, graft types, and surgical techniques, all of which might have affected outcomes. Third, clinical outcomes used in studies could not directly support the role of remnant-preserving method in ACL reconstruction. Fourth, despite statistically significant differences in terms of arthrometric evaluation, Lachman test, Lysholm scores, and IKDC subjective scores, the magnitude of difference was not large enough. Therefore, it is difficult to interpret that remnant-preserving arthroscopic ACL reconstruction method provides superior outcomes than non- 
preserving method. Thus, precautions are required when interpreting these results. Fifth, both RCTs and observational studies have only about 1 year of follow-up duration in seven of eleven studies. The outcome might be different with longer follow-up duration.

\section{Conclusion}

This meta-analysis with subgroup analysis showed that arthroscopic remnant-preserving ACL reconstruction provided statistically significant but limited clinical relevance in terms of arthrometric evaluation. Results of Lachman test, Lysholm scores, and IKDC subjective scores demonstrated statistically minor differences.

\section{Abbreviations}

ACL: Anterior cruciate ligament; Cl: Confidence intervals; ICC: Intraclass correlation coefficient; IKDC: International Knee Documentation Committee; NOS: Newcastle-Ottawa Scale; OR: Odd ratio; PEDro: Physiotherapy Evidence Database; PRISMA: Preferred Reporting Items for Systematic Review and Meta-Analysis; RCTs: Randomized controlled trials; RR: Relative risk; SIR: Standardized incidence ration; SMD: Standardized mean difference

\section{Acknowledgements}

Not applicable.

\section{Authors' contributions}

Clinical data analysis and interpretation: SHW, SYP, H-SC, B-IL. Drafting of the manuscript: SHW, H-SC. Measuring of clinical data: SHW, H-SC, G-WS, Y-BK, JHK. Clinical revision of the manuscript: SHW, H-SC, K-DM, S-WK, J-BK. Approval of final manuscript: all authors.

\section{Funding}

No funding was received.

\section{Availability of data and materials}

All data generated or analyzed during this study are included in this published data.

\section{Ethics approval and consent to participate}

Not applicable (all primary articles incorporated in this meta-analysis reported adequate ethics approval procedures).

\section{Competing interests}

The authors declare that they have no competing interests.

\section{Author details}

'Department of Orthopaedic Surgery, Soonchunhyang University Hospital Seoul, 59, Daesagwan-ro, Yongsan-gu, Seoul 04401, Korea. ²Department of Biostatistics, Soonchunhyang University Hospital, Seoul, Korea. ${ }^{3}$ Department of Orthopaedic Surgery, Soonchunhyang University Hospital, Bucheon, Korea. ${ }^{4}$ Department of Orthopaedic Surgery, Soonchunhyang University Hospital, Cheonan, Korea. ${ }^{5}$ Department of Orthopaedic Surgery, Soonchunhyang University Hospital, Gumi, Korea.

Received: 30 May 2019 Accepted: 7 November 2019

Published online: 01 January 2020

\section{References}

1. Amiel D, Kleiner JB, Roux RD, Harwood FL, Akeson WH (1986) The phenomenon of "ligamentization": anterior cruciate ligament reconstruction with autogenous patellar tendon. J Orthop Res 4:162-172

2. Marumo K, Saito M, Yamagishi T, Fujii K (2005) The "ligamentization" process in human anterior cruciate ligament reconstruction with autogenous patellar and hamstring tendons: a biochemical study. Am J Sports Med 33 1166-1173
3. Tohyama H, Yoshikawa T, Ju Y-J, Yasuda K (2009) Revascularization in the tendon graft following anterior cruciate ligament reconstruction of the knee: its mechanisms and regulation. Chang Gung Med J 32:133-139

4. Lee B-I, Min K-D, Choi H-S, Kim J-B, Kim S-T (2006) Arthroscopic anterior cruciate ligament reconstruction with the tibial-remnant preserving technique using a hamstring graft. Arthroscopy 22:340 e1-. e7

5. Zhang Q, Zhang S, Cao X, Liu L, Liu Y, Li R (2014) The effect of remnant preservation on tibial tunnel enlargement in $\mathrm{ACL}$ reconstruction with hamstring autograft: A prospective randomized controlled trial. Knee Surg Sports Traumatol Arthrosc 22:166-173

6. Tanabe Y, Yasuda K, Kondo E, Kitamura N (2016) Clinical results of anterior cruciate ligament reconstruction with ligament remnant tissue preservation: a systematic review. Asia Pac J sports Med Artrhosco Rehabil Technol 4:1-8

7. Hu J, Qu J, Xu D, Zhang T, Zhou J, Lu H (2014) Clinical outcomes of remnant preserving augmentation in anterior cruciate ligament reconstruction: a systematic review. Knee Surg Sports Traumatol Arthrosc 22(9):1976-1985

8. Ma T, Zeng C, Pan J, Zhao C, Fang H, Cai D (2017) Remnant preservation in anterior cruciate ligament reconstruction versus standard techniques: a meta-analysis of randomized controlled trials. J Sports Med Phys Fitness 57: 1014-1022

9. Tie K, Chen L, Hu D, Wang H (2016) The difference in clinical outcome of single-bundle anterior cruciate ligament reconstructions with and without remnant preservation: a meta-analysis. Knee 23:566-574

10. Gohil S, Annear PO, Breidahl W (2007) Anterior cruciate ligament reconstruction using autologous double hamstrings: A comparison of standard versus minimal debridement techniques using MRI to assess revascularisation - A randomised prospective study with a one-year followup. J Bone Joint Surg Ser B 89:1165-1171

11. Hong L, Li X, Zhang H, Liu X, Zhang J, Shen J, Feng H (2012) Anterior cruciate ligament reconstruction with remnant preservation: a prospective, randomized controlled study. Am J Sports Med 40(12):2747-2755

12. Mohtadi NG, Chan DS, Naylor A, Humphrey R (2012) Does ligament preservation during anterior cruciate ligament reconstructive surgery in anterior cruciate ligament-deficient patients improve patient-reported outcomes at 1 year? A prospective cohort study. Clin J Sport Med 22:296-297

13. Pujol N, Colombet P, Potel J, Cucurulo T, Graveleau N, Hulet C, Panisset J, Servien E, Sonnery-Cottet B, Trojani C, Djian P (2012) Anterior cruciate ligament reconstruction in partial tear: selective anteromedial bundle reconstruction conserving the posterolateral remnant versus single-bundle anatomic ACL reconstruction: preliminary 1-year results of a prospective randomized study. Orthop Traumatol Surg Res OTSR:S98(8 Suppl):171-S177

14. Qi J, Chen J, Chen S, Li Y, Hua Y, Li H, Dong Y (2010) Prospective study on anterior cruciate ligament reconstruction with preserving remnant anterior cruciate ligament by allograft ligament. Zhongguo xiu fu chong jian wai ke za zhi 24:917-921

15. Park SY, Oh H, Park SW, Lee JH, Lee SH, Yoon KH (2012) Clinical outcomes of remnant-preserving augmentation versus double-bundle reconstruction in the anterior cruciate ligament reconstruction. Arthroscopy 28:1833-1841

16. Naylor AJ, Mohtadi NGH, Chan DS, Humphrey RS, Donald M (2013) Anterior Cruciate Ligament preservation during reconstructive surgery: Does the extra surgical effort improve patient outcomes at one year? Sport Orthop Sport Traumatol 29:29-39

17. Takazawa Y, Ikeda H, Kawasaki T, Ishijima M, Kubota M, Saita Y, Kaneko H, Kim SG, Kurosawa H, Kaneko K (2013) ACL reconstruction preserving the $\mathrm{ACL}$ remnant achieves good clinical outcomes and can reduce subsequent graft rupture. Orthop J Sports Med 1(4):2325967113505076

18. Chen HH, Wang H, Guo Z, Quan LZ, Tong L, Wang H (2015) Anterior cruciate ligament reconstruction with single beam of hamstring tendon: A 1-year follow-up of knee function and stability. Chin J Tissue Eng Res 19:246-251

19. Kondo E, Yasuda K, Onodera J, Kawaguchi Y, Kitamura N (2015) Effects of Remnant Tissue Preservation on Clinical and Arthroscopic Results After Anatomic Double-Bundle Anterior Cruciate Ligament Reconstruction. Am J Sports Med 43:1882-1892

20. Lee BI, Kwon SW, Kim JB, Choi HS, Min KD (2008) Comparison of Clinical Results According to Amount of Preserved Remnant in Arthroscopic Anterior Cruciate Ligament Reconstruction Using Quadrupled Hamstring Graft. Arthroscopy 24:560-568

21. Ahn JH, Wang JH, Lee YS, Kim JG, Kang JH, Koh KH (2011) Anterior cruciate ligament reconstruction using remnant preservation and a femoral 
tensioning technique: Clinical and magnetic resonance imaging results. Arthroscopy 27:1079-89+e137

22. Howell SM, Knox KE, Farley TE, Taylor MA (1995) Revascularization of a human anterior cruciate ligament grafting during the fist two years of implantation. Am J Sports Med 23:42-49

23. Ahn JH, Lee SH, Choi SH, Lim TK (2010) Magnetic resonance imaging evaluation of anterior cruciate ligament reconstruction using quadrapled hamstring tendon autografts: comparsion of remnant bundle preservation and standard technique. Am J Sports Med 38:1769-1777

24. Kitamura N, Yasuda K, Yokota M, Goto K, Wada S, Onodera J, Kondo E (2017) The effect of intraoperative graft coverage with preserved remnant tissue on the results of the pivot-shift test after anatomic double-bundle anterior cruciate ligament reconstruction: quantitative evaluations with an electromagnetic sensor system. Am J Sports Med 45:2217-2225

25. Kim SJ, Jo SB, Kim TW, Chang JH, Choi HS, Oh HS, Oh KS (2009) A modified arthroscopic anterior cruciate ligament double-bundle reconstruction technique with autogenous guadriceps tendon graft: remnant-preserving technique. Arch Orthop Trauma Surg 129:403-407

26. Adachi N, Ochi M, Uchio Y, Sumen Y (2000) Anterior cruciate ligament augmentation under arthroscopy. Arch Orthop Trauma Surg 120:128-133

27. Duthon V, Barea C, Abrassart S, Fasel J, Fritschy D, Ménétrey J (2006) Anatomy of the anterior cruciate ligament. Knee Surg Sports Traumatol Arthrosc 14:204-213

28. Sonnery-Cottet B, Lavoie F, Ogassawara R, Kasmaoui H, Scussiato RG, Kidder JF, Chambat P (2010) Clinical and operative characteristics of cyclops syndrome after double-bundle anterior cruciate ligament reconstruction. Arthroscopy. 26:1483-1488

29. Meredick RB, Vance KJ, Appleby D, Lubowitz JH (2008) Outcome of singlebundle versus double-bundle reconstruction of the anterior cruciate ligament : a meta-analysis. Am J Sports Med 36(7):1414-1421

30. IKDC committee: AOSSM: Anderson A, Bergfel J, Boland A, et al. ESSKA: Staubli H, Hefti F, Hoher J, Jacob R, Mueller W, Neyret P. APOSSM: Chan K, Kurosaka M. 2000 IKDC Knee Forms. Available at http://www.Sportmed.org/ tabs/research/ikdc.aspx. Accessed 8 Apr 2008

31. Hu J, Qu J, Xu D, Zhang T, Zhou J, Lu H (2014) Clinical outcomes of remnant preserving augmentation in anterior cruciate ligament reconstruction: a systematic review. Knee Surg Sports Traumatol Arthrosc 22:1976-1985

\section{Publisher's Note}

Springer Nature remains neutral with regard to jurisdictional claims in published maps and institutional affiliations.

Ready to submit your research? Choose BMC and benefit from:

- fast, convenient online submission

- thorough peer review by experienced researchers in your field

- rapid publication on acceptance

- support for research data, including large and complex data types

- gold Open Access which fosters wider collaboration and increased citations

- maximum visibility for your research: over $100 \mathrm{M}$ website views per year

At BMC, research is always in progress.

Learn more biomedcentral.com/submissions 